\title{
La legislación aduanera en la nueva normalidad de la COVID-19
}

Edgar Fernando Cosío Jara

Abogado por la Pontificia Universidad Católica del Perú.

Magíster en Política Tributaria por la Universidad Nacional Mayor de San Marcos. Profesor de Derecho Aduanero y Comercio Internacional en la Universidad Nacional Mayor de San Marcos, Universidad de Piura, Universidad Nacional Federico Villareal y el Instituto de la Superintendencia Nacional de Aduanas y Administración Tributaria,

y docente invitado en la Universidad del Rosario.

Ex Intendente en las Intendencias de Aduana Marítima del Callao, Paita, lquitos, Mollendo y Tumbes. Miembro fundador de la Academia Internacional de Derecho Aduanero y Presidente de la Academia Peruana de Derecho Aduanero.

SUMARIO:

I. Antecedentes: la legislación pre-COVID-19.

II. Los efectos de la irrupción de la COVID-19 en el comercio internacional.

III. Legislación del comercio exterior frente a la COVID-19.

IV. Legislación aduanera frente a la COVID-19.

1. Las normas paperless: la digitalización de los procesos aduaneros.

2. Las medidas de alivio para los usuarios aduaneros.

2.1. La suspensión de plazos aduaneros,

2.2. Las facilidades para el cumplimiento de la deuda aduanera.

2.3. Inaplicación de sanciones.

V. A modo de conclusión. 


\title{
RESUMEN:
}

La pandemia COVID-19 tuvo un impacto en la salud y la economía nacional. En el Derecho y dentro de la ciencia jurídica, una de las legislaciones que sufrió mayores cambios fue la aduanera. Declarado el Estado de Emergencia ante la letalidad de la pandemia, solo el transporte de carga fue permitido para garantizar la cadena de suministros de alimentos y medicinas al país. Aunque en un principio el tráfico internacional de mercancías debió contraerse, luego tuvo que convertirse en uno de los motores de la reactivación para lo cual la Administración Aduanera peruana tuvo la suerte que precisamente el año 2020 había iniciado un proceso de transformación digital y legal. En este ensayo el autor analiza esta vorágine de cambios en la Aduana peruana y su impacto en la normativa y la economía nacional.

Palabras clave: Administración Aduanera, COVID19, Programa FAST, Legislación Aduanera, Comercio Exterior, SUNAT, Medidas de alivio, Sanciones Aduaneras, Aduanas 2.0, Reactivación.

\begin{abstract}
:
The COVID-19 pandemic has had an impact in health and the national economy, and in the legal sciences, one of the areas that had the most changes was customs law. When the state of emergency was declared as a result of the lethality of the pandemic, only cargo transportation was allowed in order to guarantee the pharmaceutic and food supply chain. Even though the international freight traffic contracted at the start of the pandemic, it later became one of the main engines for economic reactivation, and luckily, the Peruvian Customs Administration had started a legal and digital transformation process precisely in 2020. Throughout this essay, the author analyses this onslaught of changes in the Peruvian Customs Administration and its impact in the national legislation and economy.

Keywords: Customs Administration, COVID-19, FAST Program, customs legislation, international commerce, SUNAT, relief measures, customs penalties, Aduanas 2.0, reactivation.
\end{abstract}

\section{ANTECEDENTES: LA LEGISLACIÓN PRE-COVID-19}

El año 2020 sorprendió a la Superintendencia Nacional de Aduanas y Administración Tributaria -SUNAT, o "la Administración Aduanera"en medio de un proceso de modernización de sus plataformas informáticas en el marco del denominado Programa FAST 1 y de su legislación. ${ }^{2}$ La Ley General de Aduanas -en adelante, la Ley o LGA - y sus plataformas SIGAD - Sistema Integrado de Gestión Aduanera- y NPDA — Nuevo Proceso de Despacho Aduanero- no se adecuaban a las necesidades de los usuarios ni a las funcionalidades que demandaba la Administración, bajo los lineamientos de la Organización Mundial de Aduanas - OMA y la Organización Mundial de Comercio - OMC, cuyas normas principales - Convenio de Kioto Revisado-CKR, Marco Normativo de Seguridad y Facilitación "MARCO SAFE" y el Acuerdo de
Facilitación, "AFC" - basaban el control aduanero del siglo XXI en el manejo de información anticipada y electrónica y en actuaciones coordinadas entre las Aduanas, las Aduanas y las empresas y las Aduanas con otras entidades gubernamentales - los denominados 3 pilares del Marco SAFE- En ese contexto se había programado una transformación legal e informática en el año 2020.

Los primeros pasos para estos cambios fueron dados en materia de legislación aduanera con la modificación de la LGA por el Decreto Legislativo 1433 y su Reglamento, aprobado por el Decreto Supremo N³87-2019-EF.

En ese contexto, el 01 de enero del año 2020 entró en vigencia en materia aduanera un nuevo marco legal. La LGA estrenaba nuevos tratamientos para el Régimen de Operadores de Comercio Exterior y el Sistema de Infrac-

1. Siglas de "Programa de Facilitación Seguridad y Transparencia Aduanera".

2. En el 2020 entró en vigencia una nueva Tabla de Sanciones Aduaneras —Decreto Supremo N418-2019-EF-. 
ciones y Sanciones, y con ese fin entraban en vigencia un día antes el Decreto Legislativo 1433 -modificando completamente la Ley en sus secciones segunda y décima- y el Decreto Supremo $N^{\circ} 418-2019-E F$, que establecía un nuevo régimen sancionador, en el cual los operadores perdían los incentivos, un beneficio de rebaja en sus infracciones de hasta el $90 \%$, y pasaban a ser evaluados anualmente por la Aduana y categorizados de acuerdo a su nivel de cumplimiento. ${ }^{3}$

Paralelamente, la SUNAT ${ }^{4}$ había programado para el 2020 la implementación de su ambicioso Programa FAST, en virtud del cual se modificarían 17 procedimientos aduaneros de despacho, entre ellos los principales de Exportación Definitiva -DESPA.PG.02- e Importación para Consumo -DESPA.PG.01 versión 8- con la finalidad de facilitar, agilizar, automatizar y transparentar los procesos de entrada y salida de mercancías en las Aduanas del país, así como en los procesos complementarios de control de operadores. Todos ellos integrados a los procesos transversales de gestión de riesgo y seguridad de la cadena logística. ${ }^{5}$

EI FAST está conformado por cuatro proyectos componentes: Ingreso, Salida, Control de Operadores y Gestión de Riesgo, los cuales eran considerados piezas claves para el cumplimiento en los objetivos estratégicos - OE de la SUNAT: el OE1, mejorar el cumplimiento tributario y aduanero; y el OE2, reducir los costos de cumplimiento de las obligaciones tributarias y aduaneras.

Este Programa buscaba reducir los tiempos de despacho aduanero, eliminando trámites presenciales mediante el uso de formatos electrónicos, implementando despachos diferenciados para los $\mathrm{OEA}^{6}$ fortaleciendo el intercambio de información con los operadores de comercio exterior y el uso intensivo de tecnologías de punta a fin de mejorar la competitividad y contribuir a la mejora de los servicios aduaneros y logísticos.

Fue en ese contexto que la Organización Mundial de la Salud, a consecuencia del brote del virus SARS-CoV2, declara la situación de pandemia a nivel mundial. El Perú, mediante Decreto Supremo $N^{\circ}$ 044-2020-PCM, declaró el Estado de Emergencia Nacional y la medida de aislamiento social obligatorio a partir del 16 de marzo del 2020.

Como consecuencia del Estado de Emergencia, el PBI peruano se contrajo en $30 \%$ y el empleo se redujo en $39.5 \%$ durante el segundo

3. Como señalaba la Exposición de Motivos del Decreto Legislativo 1433 -página 97-: "El sistema de regulación de operadores no establecía ninguna consecuencia por el incumplimiento reiterado de las obligaciones aduaneras, excepto el pago de multas de muy baja cuantía, reducidas en aplicación de los regímenes de gradualidad e incentivos al pago generalizados para casi todas las infracciones sancionadas con multa. En consecuencia, el riesgo de incumplimiento era menor al riesgo de presentar declaraciones con información falsa o errada. Esta incapacidad para cumplir con la ley está relacionada también con los requisitos poco exigentes que se piden al sector privado para delegarles servicios aduaneros. Es por ello que anunciaba que si bien el nuevo sistema de infracciones y sanciones no contendría penalidades más altas "estas podrán graduarse en relación a la voluntad del infractor para mejorar la capacidad de cumplimiento, además de la evaluación de su historial y el nivel de calidad de los servicios prestados. En sentido contrario, se castigará la recurrencia y el bajo nivel de cumplimiento tendrá como consecuencia (no sólo la sanción sino) la no renovación de la delegación de servicios aduaneros".

4. Entidad responsable de la actividad aduanera peruana luego que el Decreto Supremo N418-2002-PCM estableciera un proceso de fusión por absorción que le otorgaba la condición de entidad absorbente de la extinta Superintendencia Nacional de Aduanas - SUNAD.

5. Sobre el FAST, revisar: https://www.sunat.gob.pe/operatividadaduanera/fast/index.html

6. Los OEA son los Operadores Económicos Autorizados que por su alto nivel de cumplimiento son certificados por la SUNAT para gozar de trato preferencial en despacho a nivel nacional e internacional —en aquellos países con los que el Perú ha suscrito acuerdos de reciprocidad-. 
trimestre del año. ${ }^{7}$ Frente a ello, desde el mes de junio el gobierno decidió iniciar un proceso de reactivación por etapas a fin de reducir esta caída.

En ese contexto, una de las mayores contracciones se produjo en el comercio local e internacional, y frente a ello el Estado a nivel general y la Administración Aduanera a nivel especializado, como entidad encargada del control del tráfico internacional de mercancías, debieron ajustar su normatividad a la nueva realidad, inicialmente con un nuevo enfoque de control y posteriormente con la obligación de facilitarlo para la reactivación.

\section{LOS EFECTOS DE LA IRRUPCIÓN DE LA CO- VID-19 EN EL COMERCIO INTERNACIONAL}

Antes de analizar la normativa aduanera peruana, debemos partir señalando que la pandemia creó un escenario de contracción del comercio mundial de mercancías. Tal como señala la Comisión Económica para América Latina y el Caribe _CEPAL- ${ }^{8}$, ésta alcanzó el $-18.5 \%$ en el segundo trimestre de 2020 en comparación con igual período de 2019, con un estimado anual del -13\% — similar a la caída anual en 2009-, pero cuya reversión total aún no puede definirse porque no obstante la aparición de vacunas y otros paliativos contra la pandemia, las tasas de contagio aún siguen en aumento.

Esta situación fue más grave en la región lati- noamericana, donde el valor de las exportaciones e importaciones de bienes se redujo un $17 \%$ entre enero y mayo de 2020 en comparación con el mismo período de 2019. Ambos flujos se desplomaron hacia el final del período de cinco meses en 2020, con una caída interanual del $37 \%$ en mayo. ${ }^{9}$

Gran parte de esta disminución se originó a causa de que muchos países implementaron restricciones o prohibiciones para proteger la vida o salud humana, animal o vegetal amparándose en el artículo XX del GATT —General Agreement on Tariffs and Trade, versión 1994de excepciones generales. Sin embargo, la aplicación de esta medida solo sería reconocida por la OMC si es la opción menos restrictiva para lograr sus objetivos de política, por lo que se encuentran bajo evaluación.

A ello se suma que a nivel mundial, la CEPAL identificó que el comercio marítimo por contenedores siguió una tendencia descendente desde la irrupción de la pandemia - $6.1 \%$ en América Latina-, y a pesar de ello los fletes del transporte de contenedores se mantuvieron por encima de los valores de 2019. En el caso de la carga aérea la situación fue peor, y se asistió a la peor crisis de su historia con una caída del $46 \%$ en mayo.

En ese contexto, la proyección anual para la región arroja una contracción del tráfico internacional de mercancías, objeto del control aduanero, cercana al 30\% - ver cuadro 1 -

7. Como señala el Instituto Peruano de Economía-IPE —-Boletín IPE: Impacto del COVID-19 en Perú y Latinoamérica", en Instituto Peruano de Economía, acceso el 7 de febrero de 2021, https://www.ipe.org.pe/portal/boletin-ipe-impacto-del-covid-19-la-economia-peruana-y-latinoamerica/- la contracción de la economía peruana estuvo por encima de las caídas registradas en las demás economías de la región. En concreto, el mes de mayor impacto fue abril, en el que la economía del país se contrajo en 39.9\%, mayor a las caídas registradas en Argentina (-25.5\%), Colombia (-20.2\%), México (-19.9\%), Brasil (14.3\%) y Chile (-14.2\%). Por su parte, el empleo en el país se redujo en $39.5 \%$ a nivel nacional, en el trimestre abril-junio. Mientras tanto, la contracción de la PEA ocupada en Chile, Colombia y Argentina bordeaba el $20 \%$ en el mismo periodo. Por su parte, la caída del empleo en Brasil fue menor (-10.7\%).

8. CEPAL, "Los efectos del COVID-19 en el comercio internacional y la logística”, Informe Especial COVID-19 Nº.

9. Íbidem. 


\section{Cuadro 1}

América Latina y el Caribe: variación proyectada del valor del comercio de bienes, por socios, 2020 -en porcentajes-

\begin{tabular}{l|c|c} 
& Exportaciones & Importaciones \\
\hline Mundo & -23 & -25 \\
\hline Estados Unidos & -32 & -32 \\
\hline Unión Europea & -16 & -24 \\
\hline Asia & -7 & -23 \\
\hline China & -4 & -27 \\
\hline Resto de Asia & -11 & -19 \\
\hline América Latina & & \\
y el Caribe & -28 & -29
\end{tabular}

Fuente: Comisión Económica para América Latina y el Caribe CEPAL-, sobre la base de información de los bancos centrales, servicios de aduanas e institutos de estadística de los países.

Como consecuencia de ello, la CEPAL considera que la pandemia probablemente reforzará dos tendencias interrelacionadas en el comercio mundial:

a) La tendencia hacia un menor nivel de interdependencia productiva, comercial y tecnológica entre las principales economías mundiales -en particular entre los Estados Unidos y Europa, por una parte, y China, por la otra-. b) La tendencia hacia un comercio mundial con un menor nivel de apertura, más permeado por consideraciones geopolíticas y de seguridad nacional, con una mayor presencia de conflictos y con una institucionalidad multilateral debilitada. El resultado neto no sería una reversión de la globalización, sino una economía mundial más regionalizada, organizada en torno a tres grandes polos productivos: América del Norte, Europa y Asia Oriental y Sudoriental.

De esta manera, podemos apreciar como a nivel mundial y regional la irrupción de la $\mathrm{CO}$ VID-19 trajo consigo una contracción del comercio internacional de bienes, por el cierre de las grandes fábricas, la reducción de los flujos de comercio marítimos y aéreos, los sobrecostos, el cierre de fronteras y del transporte, además de restricciones para las exportaciones de insumos médicos e incluso alimentos.

A partir del nuevo entorno de pandemia la CEPAL identificó las consecuencias inmediatas y las oportunidades que ello generaba en la región lo que sirvió a los países latinoamericanos para implementar sus medidas de reactivación — ver figura 1-.

\section{Figura 1: PROBLEMAS Y OPORTUNIDADES DE LA CRISIS COVID-19}

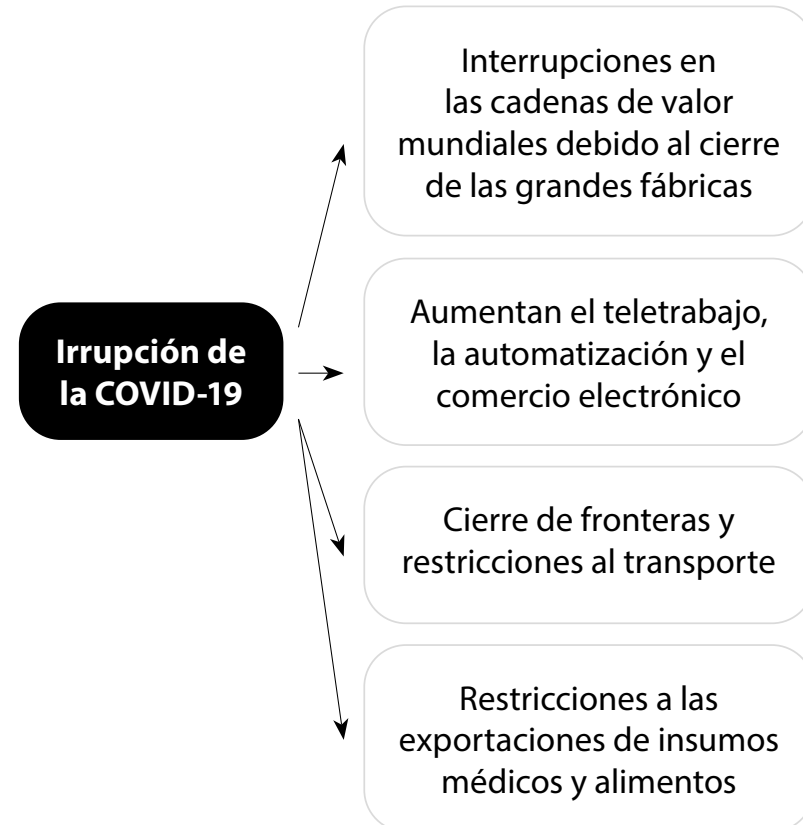

Impulsar las cadenas de valor regionales en sectores estratégicos para aprovechar la escala que ofrece un mercado de 650 millones de personas

Impulsar el comercio sin papeles y un mercado común digital

Reducir la vulnerabilidad de la región ante choques externos

Generar un diálogo en un mayor pie de igualdad con los Estados Unidos, China y Europa 
En ese escenario internacional la Administración Aduanera se convierte en un servicio esencial para mantener la vida humana, no sólo como garante de la cadena logística de suministro que incluye la importación de bienes esenciales relacionados con la COVID-19 como equipos de protección, pruebas, vacunas, medicamentos e inclusive alimentos - sino también para preservar la recaudación tributaria, la economía y otros objetivos, en una época de crisis.

De esta manera, para realizar su labor, la Aduana debió establecer prioridades destinadas a mantener el flujo continuo de las cadenas de suministro, además de proteger a la sociedad y promover la seguridad del personal. ${ }^{10}$

\section{LEGISLACIÓN DE COMERCIO EXTERIOR FRENTE A LA COVID-19}

En el caso peruano, mediante Decreto Supremo $N^{\circ}$ 044-2020-PCM se declaró el Estado de Emergencia nacional y la medida de aislamiento social obligatorio a partir del 16 de marzo del 2020. No obstante ello, el ingreso y salida de mercancías del país por puertos, aeropuertos y puntos de frontera habilitados no se vio afectado por el cierre temporal de fronteras." En consecuencia, la Administración Aduanera no dejaba de operar, ni tampoco los operadores de comercio e intervinientes en el despacho de mercancías. ${ }^{12}$
En el nuevo marco del comercio de bienes en pandemia, el Perú con su política de libre comercio instaurada en 1991 -Decreto Legislativo 668 - y consolidada con la Constitución Política de 1993 —artículo 63- que implica una política de apertura al mundo tanto para las importaciones como las exportaciones reduciéndose los controles al arancel y las listas de mercancías prohibidas o restringidas-, encontró que ella podía tener un efecto boomerang, ya que la mayoría de países demandaba las mismas mercancías - medicinas, equipos de protección y productos vinculados-, lo que podría generar una situación de indefensión frente a la salida indiscriminada de este tipo de bienes. Es por ello que dicha libertad debió, en principio, subordinarse ante el derecho superior a la salud y la vida que se ponían en juego en esta pandemia, en concordancia con las excepciones del artículo XX del GATT y la propia jurisprudencia constitucional. ${ }^{13}$

Es por ello que, siguiendo a Guzmán Barrón ${ }^{14}$, al estar la política aduanera subordinada a la política de comercio exterior de un Estado, las primeras medidas se dieron para regular los flujos de mercancías - cada vez más reducidos - frente a una demanda de equipos e instrumental médico y productos de limpieza o farmacéuticos que los países se disputaban en el mercado internacional. Para ello, se revir-

10. Fondo Monetario Internacional, Medidas prioritarias para las administraciones aduaneras, https://www.imf. org/ /media/Files/Publications/covid19-special-notes/Spanish/sp-special-series-on-covid-19-priority-measures-for-customs-administration.ashx, 2.

11. Artículo 8, numeral 3 del Decreto Supremo N044-2020-PCM:

"8.3 El transporte de carga y mercancía no se encuentra comprendido dentro de este cierre temporal. Las autoridades competentes adoptan las medidas necesarias para garantizar el ingreso y salida de mercancías del país por puertos, aeropuertos y puntos de frontera habilitados"

12. Cfr. Resolución Ministerial N 0232-2020-MTC/01.02.

13. STC N ${ }^{\circ}$ 05961-2009-PA/TC Precedente vinculante: Transportes Vicente, Eusebio, Andrea SAC, donde el supremo intérprete prohibió la importación de autos usados causantes de accidentes y contaminación ponderando los derechos constitucionales y colocando el derecho a la vida y la salud por encima de los derechos a la libertad de empresa y de contratación.

14. César Guzmán Barrón, “La misión de la aduana en el régimen de apertura del comercio exterior". Thēmis 31 (1995), 23. 
tió la política liberal luego de casi 30 años a fin de evitar que no sólo respiradores artificiales, pruebas moleculares sino también mascarillas de protección, guantes y equipos de protección médica o alcohol en gel salgan sin control del país. De esta manera, el Decreto Supremo $\mathrm{N}^{\circ}$ 015-2020-SA del 16 de abril del 2020 aumentó la lista de mercancías de exportación restringida para incluir a estas últimas.

Por otro lado, a fin de facilitar el acceso a elementos de protección médica y productos farmacéuticos que permitan mejorar nuestro sistema de salud contra la pandemia, se estableció un arancel cero temporal en 77 partidas arancelarias anteriormente gravadas con tasas de $6 \%$ y $11 \%$-Decretos Supremos $N^{\circ} 051-2020-E F$ y 059-2020-EF-; y adicionalmente, a fin de que la ayuda internacional contra la COVID-19 Ilegue a tiempo y sin contratiempos, se aprobó el Decreto Legislativo 1460 que flexibiliza el procedimiento para la aceptación de donaciones provenientes del exterior a entidades públicas con cargo a su regularización hasta 30 días calendario siguientes al término de la emergencia sanitaria.

Finalmente, mediante el Decreto Legislativo 1492 , se declara prioritaria la reactivación continuidad y eficiencia de las operaciones logísticas del comercio exterior, vinculadas al ingreso y salida de mercancías y medios de transporte de carga desde o hacia el país y se establece como obligaciones de las entidades del Estado involucradas, entre otras acciones:

a) Garantizar la atención de sus procedimientos salvaguardando las medidas sanitarias contra la COVID-19 para lo cual deben utilizar medios electrónicos —artículo 4 del Decreto Legislativo-.

b) Que las entidades públicas que exijan o generen documentos o información relacionada a los procesos vinculados a la cadena logística de comercio exterior, incluyendo los servicios de transporte de carga y mercancías en general en todos sus modos, deben automatizar sus procesos, reemplazar documentos físicos por documentos digitales o digitalizados, e intercambiar datos entre ellas, a fin de evitar el contacto usuario-administración -artículo 5 del Decreto Legislativo-.

c) Efectuar las inspecciones físicas para el ingreso de carácter sanitario, aduanero o de otra índole, sin exigir documentos originales, cuando exista copia simple digitalizada en la Ventanilla Única de Comercio Exterior - VUCE o en el Sistema informático de la SUNAT u otros contemplados en la legislación vigente.

d) Establecer mecanismos de gestión de riesgo, y efectuar fiscalización posterior de la documentación presentada por medios electrónicos -artículo 6 numeral 2 del Decreto Legislativo-, ello en concordancia con el Texto Único Ordenado de la Ley 27444, Ley del Procedimiento Administrativo General —en adelante, "TUO de la LPAG"-

El propio Decreto Legislativo 1492 incluso asumió una función tuitiva del Estado en el comercio internacional respecto a la digitalización de los procesos y trámites logísticos por parte del sector privado -artículo 7-. En ese sentido, exigió a los operadores de comercio exterior incorporar en sus procesos sistemas de intercambio de datos o mecanismos electrónicos alternos necesarios para la validación de documentos o información, tales como el uso de documentos digitales o digitalizados, con el objeto de evitar el desplazamiento de personas con el consiguiente riesgo de contagio de la COVID-19. En ese sentido, indicó expresamente a las navieras o sus representantes:

“(...) poner a disposición de sus clientes y/o usuarios del servicio, sistemas u otros mecanismos electrónicos que faciliten el cumplimiento de sus procesos o trámites, necesarios para la autorización comercial de la entrega y/o embarque de la mercancía, así como para facilitar los trámites que correspondan para el recojo y/o devolución de contenedores, equipos u otros dispositivos utilizados para el

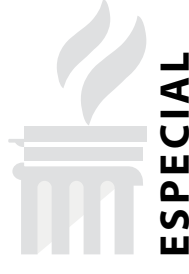

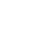


desarrollo del transporte de carga y mercancías. (...) $)^{\prime \prime 15}$

De igual manera, en el artículo 7 numeral 3, ordenó a los almacenes aduaneros y agentes de carga poner a disposición de sus clientes y/o usuarios de su servicio, sistemas u otros mecanismos electrónicos que faciliten el ingreso o entrega de la mercancía, según corresponda.

La implementación de estas medidas quedó a cargo del Ministerio de Comercio Exterior y Turismo en coordinación con el Ministerio de Transportes y Comunicaciones - artículo 8.1-, siendo competencia del primero la fiscalización y sanción -artículo 10-.

Este marco general destinado a regular los flujos de comercio durante el aislamiento social obligatorio fue posteriormente reemplazado con el Decreto Supremo 080-2020-PCM del 03 de mayo del 2020, que estableció el cronograma para la reactivación económica luego del aislamiento obligatorio de manera gradual y progresiva, en 4 fases que se iniciaron ese mismo mes. Este proceso se denominó la "Nueva Normalidad".

Con la Fase 1, la Aduana dejó de atender únicamente los tramites vinculados a temas de salud y alimentación, y empezó a facilitar otros procesos, permitiéndose las exportaciones con órdenes de compra vencidas o por vencer antes de la vigencia del Decreto Supremo y las importaciones vinculadas a las actividades comprendidas dentro de la Fase 1, lo que incluye la actividad minera, de hidrocarburos, construcción, comercio electrónico para el hogar, industria del vidrio, papel, entre otras.

Para la implementación de esta apertura gradual, el Decreto de Urgencia 053-2020, a fin de aliviar los riesgos de abandono e infracción por vencimiento de plazos para los Operadores, otorgó una prórroga adicional de 15 días hábiles para el cumplimiento de sus obligaciones.

Con ese marco legal general correspondió a la Administración Aduanera el diseño de los procedimientos en época de cuarentena y en época de reactivación.

\section{LA LEGISLACIÓN ADUANERA FRENTE A LA COVID-19}

Frente a un control aduanero que en base a la gestión de riesgos incluye un reconocimiento físico de hasta el $15 \%$ de las declaraciones presentadas a despacho ${ }^{16}$ y en el resto de casos el control documentario de la Declaración aduanera de mercancías -DAM - con sus documentos de soporte - contemplados en el artículo 60 del Reglamento de la Ley-, la Aduana tuvo que reenfocar sus procesos, en concordancia con los lineamientos del Decreto Legislativo 1492 con el objeto de evitar el desplazamiento de personas por el consiguiente riesgo de contagio de la COVID-19. Esto alcanzaba a todos sus procedimientos administrativos incluido su proceso principal, el despacho aduanero, entendido como el trámite ante la Administración Aduanera que se inicia con la presentación de la declaración y concluye con su autorización para el desaduanamiento de la

15. Decreto Legislativo 1492, artículo 7 numeral 2.

16. Cfr. Artículo 163 de la LGA:

"Empleo de la gestión del riesgo

Para el ejercicio del control aduanero, la Administración Aduanera emplea, principalmente las técnicas de gestión de riesgo para focalizar las acciones de control en aquellas actividades o áreas de alto riesgo, respetando la naturaleza confidencial de la información obtenida para tal fin.

Para el control durante el despacho, la Administración Aduanera determina mediante técnicas de gestión de riesgo los porcentajes de reconocimiento físico de las mercancías destinadas a los regímenes aduaneros, que en ningún caso debe exceder del $15 \%$ de las declaraciones numeradas.

En el caso de mercancías restringidas, la selección a reconocimiento físico se realiza en base a la gestión de riesgo efectuada por la Administración Aduanera, en coordinación con los sectores competentes" 
carga - sea con su levante e ingreso al país o para su embarque con destino al exterior-.

Ante esta nueva situación, las modificaciones legales y tecnológicas de inicios del 2020, Decreto Legislativo 1433, Nueva Tabla de Sanciones y Proyecto FAST, en lugar de postergarse ante la Nueva Normalidad de la COVID-19, se convirtieron en un catalizador para los nuevos procesos. De esta manera se procedió a la adopción de ciberprocedimientos aprovechando la infraestructura normativa y tecnológica, que había empezado a implementarse en base al nuevo marco legal del Decreto Legislativo 1433 .

Como medidas complementarias de alivio se adoptaron normas a nivel Resolución de Superintendencia destinadas a la suspensión de los plazos a fin de evitar la congestión de los recintos aduaneros, la inaplicación de sanciones en el marco de las facultades discrecionales previstas en la en la LGA y algunas facilidades para el cumplimiento de las deudas aduaneras derivadas del despacho.

De esta manera la digitalización de los procedimientos -Administración Aduanera 2.0 o Aduana paperless - y las medidas de alivio para los usuarios de comercio exterior como la suspensión de plazos, las facilidades de pago y la discrecionalidad para no aplicar sanciones, se convirtieron en el eje de la normativa aduanera durante la pandemia de la COVID-19.

\section{Figura 2}

\section{PAQUETE ADUANERO CONTRA EL COVID-19}
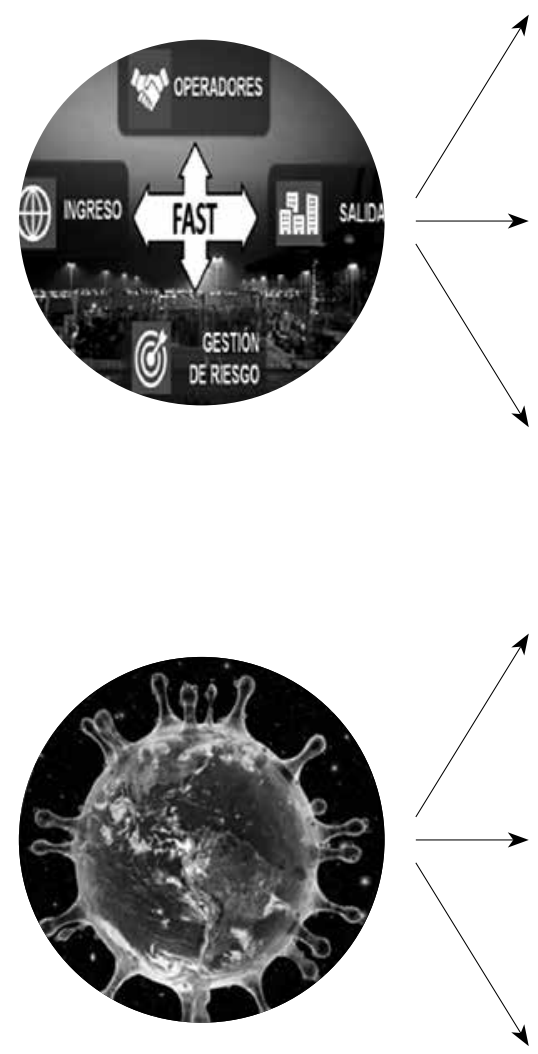

ADMINISTRACIÓN ADUANERA 2.0

-ADUANA PAPERLESS-

DECRETO LEGISLATIVO 1492

- Mesa de partes virtual - Resolución N 077-2020-SUNAT-

- Procedimientos Aduaneros Digitalizados-FAST

-Resoluciones SUNAT No $122,169,172,176,182,184,185$,

199, 200-

\section{MECANISMOS LEGALES DE ALIVIO:}

- Suspensión de plazos —Decretos de Urgencia 026 y 029-2020-

- Facilidades tributarias

- Arancel cero para mercancías contra la COVID-19 -Decretos Supremos No 051 y 059-2020-EF-

- Régimen especial fraccionamiento y aplazamiento - Decreto Legislativo 1487-

- Inaplicación de sanciones

- Resoluciones SUNAT de discrecionalidad para sanciones de nueva tabla - Resoluciones SNAA-

- Gradualidad para tabla anterior - Resolución $\mathrm{N}^{\circ}$ 156-2020-SUNAT-

- No se afecta récord de cumplimiento de los OCE -Resolución N²26-2020-SUNAT- 
1. Las normas paperless: la digitalización de los procedimientos aduaneros.

El uso de la Tecnología de la Información $\mathrm{TIC}$ - no era una novedad en los procedimientos administrativos en general y los procedimientos aduaneros en particular. De hecho, las principales directrices de la OMA y la OMC, organismos internacionales creadores de las normas técnicas globales en materia aduane$\mathrm{ra}$, apuntaban a una Aduana sin papeles - $\mathrm{pa}$ perless - que hiciera sinergia con el desarrollo del comercio electrónico en todas sus modalidades. Así lo señalaba la LGA en su artículo 5 cuando establecía que la Administración debía "disponer medidas para que el intercambio de datos y documentos entre la autoridad aduanera y los operadores de comercio exterior se realicen por medios electrónicos".

A nivel del Estado Peruano, en materia de procedimientos administrativos, con el Decreto Legislativo 1412 se había aprobado la Ley de Gobierno Digital -e-government-, que establecía un régimen jurídico aplicable al uso transversal de tecnologías digitales para la digitalización de procesos y prestación de servicios digitales por parte de las entidades de la $\mathrm{Ad}$ ministración Pública en los tres niveles de go- bierno. En ese contexto, se había modificado el TUO de la LPAG y los Decretos Legislativos 1272 y 1452, estableciendo las bases para un ciberprocedimiento administrativo donde coinciden notificación electrónica, expediente electrónico, resoluciones electrónicas y firma digital.

Este procedimiento administrativo electrónico, como señalan Patrón Bedoya y Díaz García ${ }^{17}$, se concibe como un derecho de los administrados y ya no como una prerrogativa de la Administración y no era otra cosa que el procedimiento administrativo tradicional con soporte electrónico, por lo cual también debía respetar las reglas del debido procedimiento administrativo. ${ }^{18}$

El uso del procedimiento electrónico como política transversal del gobierno encuadraba perfectamente dentro de lo establecido por el Código Tributario -artículos 104, 111 y 112-y la LGA, donde el envío de información por los usuarios tenía como eje la transmisión anticipada y electrónica de los manifiestos de las naves y las declaraciones y en el caso de utilización de medios documentales la validez de estos estos debía subordinarse al medio electrónico. ${ }^{19}$

Dentro de ese marco, la SUNAT, como líder de

17. Pedro Patrón Bedoya y Mónica Díaz García, “Procedimiento administrativo electrónico”. Lumen 14-I (2008) 108.

18. El artículo 29-A de la LPAG establece que el procedimiento administrativo electrónico deberá respetar todos los principios, derechos y garantías del debido procedimiento previsto en la LPAG, sin que se afecte el derecho de defensa ni la igualdad de las partes. Doctrinariamente, como señalan Patrón y Díaz —op. cit. p. 108 — el debido procedimiento comprende el derecho a ser notificados, acceder al expediente, refutar los cargos, exponer argumentos, ofrecer y producir pruebas, obtener una decisión motivada y fundada en derecho, emitida por autoridad competente y en un plazo razonable, entre otros. Pero adicionalmente, debe tener en consideración que la declaración de la voluntad administrativa se debe conformar luego de seguir un procedimiento predeterminado por Ley.

19. Cfr. Artículo 134 de la LGA:

"Declaración aduanera

La destinación aduanera se solicita mediante declaración aduanera presentada o transmitida a través de medios electrónicos y es aceptada con la numeración de la declaración aduanera. La Administración Aduanera determinará cuando se presentará por escrito.

Los documentos justificativos exigidos para la aplicación de las disposiciones que regulen el régimen aduanero para el que se declaren las mercancías podrán ser presentados en físico o puestos a disposición por medios electrónicos en la forma, condiciones y plazos que establezca la Administración Aduanera.

Los datos transmitidos por medios electrónicos para la formulación de las declaraciones gozan de plena validez legal. En caso se produzca discrepancia en los datos contenidos en los documentos y archivos de los operadores de comercio exterior con los de la SUNAT, se presumen correctos éstos últimos.

La declaración efectuada utilizando una técnica de procesamiento de datos incluirá una firma electrónica u otros medios de autenticación. 
gobierno digital en la actividad aduanera Decreto Supremo 033-2018-PCM-, estableció una serie de acciones para eliminar en lo posible dos fuentes de contagio de la COVID-19: el uso de documentos físicos y la actividad presencial de la autoridad aduanera. Se adoptaron así las siguientes medidas propias de una Administración Aduanera 2.0:

a) La presentación de documentos a través del uso de la Casilla Electrónica, en reemplazo de la presentación física en los procesos siguientes:

(i) Acogimiento a la restitución de derechos arancelarios.

(ii) Regularización de las declaraciones de exportación definitiva numeradas en la plataforma del SIGAD.

(iii) Numeración y autorización de declaraciones de tránsito aduanero internacional.

(iv) Legajo de Declaraciones.

b) La creación de la Mesa de Partes Virtual MPV - y el Centro de Servicios Virtual con la finalidad de facilitar a los administrados la presentación, por esa vía, de documentos que se presentan de manera presencial, así como su consulta a través de esta plataforma puesta a disposición en el Portal de la SUNAT. Los Procedimientos que podrán tramitarse en MPV-SUNAT: solicitudes de devolución, recursos impugnatorios -reclamaciones y apelaciones-, inscripción y baja del RUC, entre otros. ${ }^{20}$

c) La aprobación de los nuevos procedimientos de despacho dentro del programa FAST, que incluían la transmisión electrónica de las declaraciones y el uso de la MPV para los documentos complementarios. De esta manera se aprobaron ${ }^{21}$ los procedimientos correspondientes a 12 de los 13 regímenes aduaneros regulados por la LGA, entre ellos el de Importación para Consumo — versión 8-y el de Exportación Definitiva — versión 7-, además de los tratamientos especiales más empleados como Envíos de entrega rápida y Envíos postales, y otros más específicos como Duty Free y Material de Guerra.

Con todas estas medidas se redujo al mínimo el contacto social en las Aduanas, donde inclusive la diligencia de control de mayor tradición, el aforo físico, fue reemplazado por el uso de tecnología no intrusiva o scanner ${ }^{22}$, o por un aforo remoto mediante videocámaras. ${ }^{23}$

La clave electrónica asignada a los despachadores de aduana equivale y sustituye a su firma manuscrita o a la del representante legal, según se trate de persona natural o jurídica, para todos los efectos legales."

20. Cfr. Resolución de Superintendencia N 077-2020-SUNAT.

21. Cfr. Resoluciones de Superintendencia $N^{\circ}$ 24-2020-SUNAT, 84-2020-SUNAT, 71-2020-SUNAT, 172-2020-SUNAT, 176-2020-SUNAT, 180-2020-SUNAT, 182-2020-SUNAT, 183-2020-SUNAT, 184-2020-SUNAT, 185-2020-SUNAT y 199-2020-SUNAT.

22. Cfr. Artículo 164 de la LGA:

"Potestad aduanera

Potestad aduanera es el conjunto de facultades y atribuciones que tiene la Administración Aduanera para controlar el ingreso, permanencia, traslado y salida de personas, mercancías y medios de transporte, dentro del territorio aduanero, así como para aplicar y hacer cumplir las disposiciones legales y reglamentarias que regulan el ordenamiento jurídico aduanero.

La Administración Aduanera dispondrá las medidas y procedimientos tendientes a asegurar el ejercicio de la potestad aduanera.

Los administradores y concesionarios, o quienes hagan sus veces, de los puertos, aeropuertos, terminales terrestres y almacenes aduaneros, proporcionarán a la autoridad aduanera las instalaciones e infraestructura idóneas para el ejercicio de su potestad."

23. Cfr. Informe $\mathrm{N}^{\circ} 76-2020-\mathrm{SUNAT}-340000$. 


\section{Las medidas de alivio para los usuarios aduaneros.}

La pandemia de la COVID-19 trajo para la mayoría de los países y en especial para el Perú un grave déficit económico. En ese contexto, se requerían medidas de alivio para las empresas con dificultades económicas, lo que incluye medidas para facilitar aún más el comercio y reducir los costos de las transacciones comerciales. De esta manera, la suspensión de plazos, las facilidades impositivas y la reducción de sanciones también formaron parte del paquete de cambios aduaneros.

\subsection{La suspensión de plazos aduaneros.}

La inamovilidad social obligatoria derivada del Estado de Emergencia Nacional implicaba que los usuarios aduaneros no pudieran cumplir con la presentación de documentación dentro de los plazos legales. Frente a ello, a nivel general el Decreto de Urgencia 026-2020, en su Disposición Complementaria Final Segunda dispuso la suspensión por 30 días hábiles contados a partir del día siguiente de su publicación del cómputo de los plazos de tramitación de los procedimientos administrativos sujetos a silencio positivo y negativo que a su fecha de entrada en vigencia estuvieran en trámite. Este plazo de suspensión fue prorrogado hasta el 10 de junio del 2020 -Decretos Supremos $N^{\circ} 076$ 2020-PCM y N ${ }^{\circ}$ 087-2020-PCM-.

A la vez, con Decreto de Urgencia 029-2020 se suspendió por treinta días hábiles contados desde el 21 de marzo del 2020 el cómputo de los plazos de inicio y de tramitación de los procedimientos administrativos y de los procedimientos de cualquier índole que no estuvieran comprendidos en los alcances del Decreto de Urgencia 026-2020, incluidos aquellos que a su fecha de entrada en vigencia estuvieran en trámite; plazo de suspensión que fue prorrogado hasta el 10 de junio del 2020 -Decreto de Urgencia 053-2020 y Decreto Supremo N ${ }^{\circ} 087-2020-P C M-$. Con la vigencia de ambas normas, se creó una dicotomía en materia de suspensión de plazos en los procedimientos aduaneros, porque la regulada por el Decreto de Urgencia 026-2020 aplicaba únicamente sobre los procedimientos administrativos sujetos a silencio positivo y negativo - lo que no incluía los procedimientos de fiscalización y de cobranza coactivamientras que la suspensión ordenada por el Decreto de Urgencia 029-2020 aplicaba para el resto de procedimientos pero con distinto plazo de vigencia.

Frente a esta situación, a fin de aliviar la incertidumbre de los usuarios aduaneros ante la existencia de dos plazos, la Administración Aduanera precisó que, independientemente de lo establecido en los Decretos de Urgencia, de conformidad con el artículo 138 de la LGA, en todos los procedimientos de competencia de la Aduana el plazo de los trámites y regímenes se suspende por caso fortuito o fuerza mayor, por considerar que dicha circunstancia "se presenta en la coyuntura actual, en la que por efecto de la declaración del Estado de Emergencia Nacional, el administrado se encuentra impedido de cumplir con sus obligaciones en forma oportuna".24

De esta manera, se produjo la suspensión automática de plazos para procesos como la importación para el consumo en supuestos como abandono legal, prórroga para el despacho diferido, regularización de despachos urgentes y anticipados, regularización de las declaraciones y solicitudes de reconocimiento físico acogidas al Convenio PECO y/o Ley de Amazonía.

En otros regímenes, también permitió su regularización extemporánea sin sanción -como en el de internamiento de vehículos de turismo que declarada la pandemia no pudieron salir del país y que requerían regularizar su salida-.

\subsection{Las facilidades para el cumplimiento de la deuda aduanera.}

En cuanto a estas medidas de alivio, el Poder Ejecutivo sentó las bases cuando por Decretos 
Supremos $N^{\circ}$ 051-2020-EF y 059-2020-EF modificó temporalmente los derechos arancelarios a la importación de los bienes necesarios para la atención, estableciendo una tasa arancelaria cero a 77 subpartidas arancelarias que, vencido el Estado de Emergencia retornarían a su nivel de $6 \%$ y $11 \%$ según corresponda.

Posteriormente, mediante Decreto Legislativo 1487 — vigente desde el 11 de mayo del 2020_, se estableció un Régimen de aplazamiento y/o fraccionamiento - RAF- de las deudas tributarias administradas por la SUNAT para aquellos contribuyentes que han sufrido una disminución de sus ingresos en el 2020.

En materia aduanera, se podían acoger al RAF las deudas contenidas en liquidaciones de cobranza que se encuentren pendientes de pago a la fecha de presentación de la solicitud de acogimiento, vinculadas a una resolución de determinación o resolución de multa de la Tabla de Sanciones aplicables a las infracciones previstas en la LGA o en la Ley de los Delitos Aduaneros; así como los saldos de un aplazamiento y/o fraccionamiento anterior, vigente o con causal de pérdida, a la fecha de presentación de la solicitud de acogimiento. Mediante Decreto Supremo $N^{\circ}$ 285-2020-EF, se amplió hasta el 31 de diciembre de 2020 el plazo para la presentación de la solicitud de acogimiento.
A nivel SUNAT, la Administración Aduanera dictó algunas medidas para facilitar el pago, tales como:

a) La prórroga del plazo para la ejecución de fianzas, cartas fianzas y pólizas de caución cuyo vencimiento se produzca durante el Estado de Emergencia Nacional, este plazo se suspende y recién se reanuda con la conclusión de dicho estado hasta cumplir el plazo dispuesto en el artículo 1898 del Código Civil u otra disposición de carácter específico.

b) La disminución de la tasa de interés moratorio de $1.2 \%$ a $1 \%$ en las deudas aduaneras exigibles. ${ }^{25}$

c) El pago electrónico de la deuda tributaria aduanera con los fondos de la cuenta de detracciones. ${ }^{26}$

Con estas medidas, pese a la baja recaudación del segundo trimestre del 2020 — periodo de aislamiento-, la recaudación aduanera fue recuperándose en los meses siguientes - periodo de reactivación-. De esta manera, pese a que el ejercicio 2020 se cerró con una recaudación negativa en $10.5 \%$ - S/ 26,805 millonesen relación al 2019 —S/ 29,939 millones-, en los meses de noviembre y diciembre se obtuvo niveles de recaudación superiores a los del ejercicio anterior - ver figura 3-.

\section{Figura 3: RECAUDACIÓN ADUANERA 2020}

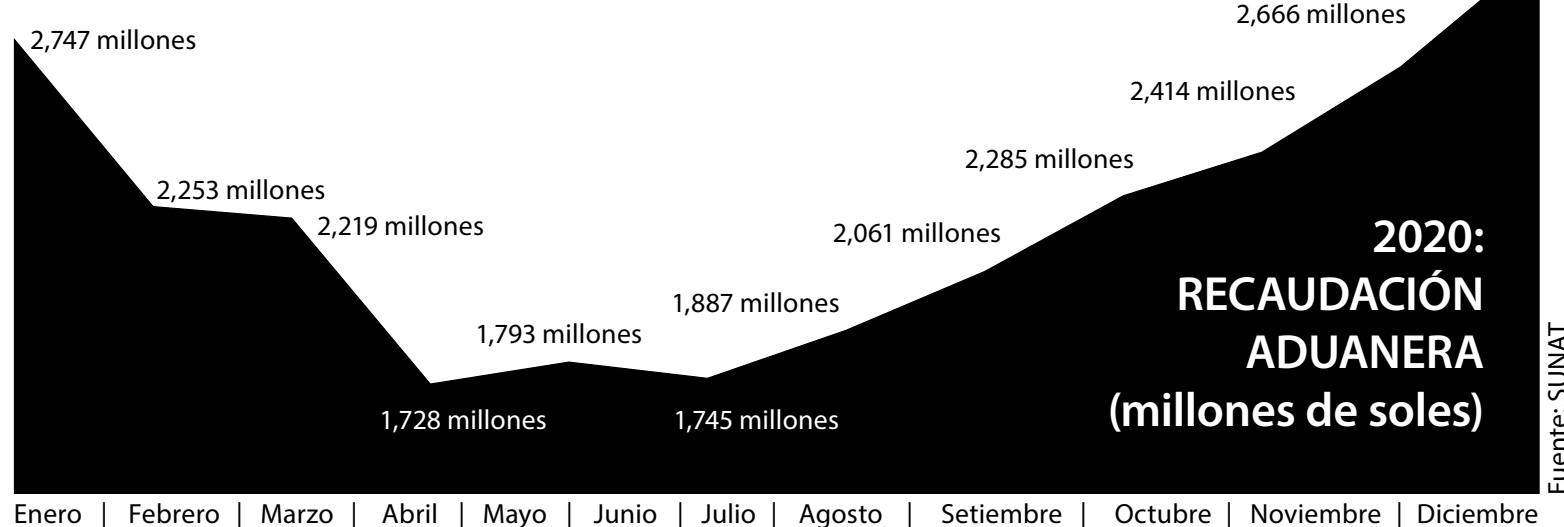

25. Cfr. Resolución de Superintendencia N 066-2020-SUNAT.

26. Cfr. Resolución de Superintendencia N²16-2020-SUNAT. 


\subsection{Inaplicación de sanciones.}

Un último aspecto para aliviar la situación de los usuarios estuvo vinculado a la aplicación de sanciones. Paradójicamente, el inicio del Estado de Emergencia coincidía con la vigencia del Decreto Supremo № 418-2019-EF, que había establecido una nueva Tabla y un nuevo régimen donde los operadores que cometían infracciones no solo recibían la sanción correspondiente sino reducían su puntaje para renovar la autorización, de forma que el cumplimiento menor a $60 \%$ podía significar la eliminación de su patente ${ }^{27}$; y no solo ello, sino que obligaba a los importadores a utilizar el sistema anticipado de despacho bajo apercibimiento de sanción.

Además, el Decreto Legislativo 1433 había derogado el Régimen de Incentivos que otorgaba a los infractores rebajas del $90 \%$ de las multas, lo que hubiera constituido el principal alivio para los operadores pero cuya eliminación fue precisamente una de las razones principales de la modificatoria legal, dado que el Informe del Banco Mundial sobre la Aduana peruana señalaba que era un "sistema perverso" porque premiaba el actuar ilícito con penas leves sin ninguna razonabilidad, ya que no distinguía si se trataba de una infracción grave o de un operador de comercio reincidente. ${ }^{28}$

En ese contexto, la alternativa que encontró la Administración Aduanera para no castigar los incumplimientos de los operadores con penalidades que agraven su difícil situación económica y mantener la razonabilidad del sistema fue aplicar su facultad discrecional para no determinar ni sancionar infracciones previstas en la LGA, cometidas en el período del 12 de marzo del 2020 al 09 de junio del 2020.

Las infracciones no sancionadas eran aquellas calificadas como leves ${ }^{29}$, exceptuándose aquellas que conlleven incidencia tributaria, burla a

27. Cfr. Reglamento de la LGA: artículos 19 y 21:

"Artículo 19".

Las categorías del operador de comercio exterior y sus rangos de calificación son los siguientes:

a) Categoría A: nivel de cumplimiento mayor o igual a $90 \%$.

b) Categoría B: nivel de cumplimiento mayor o igual a $60 \%$ y menor a $90 \%$.

c) Categoría C: nivel de cumplimiento menor a $60 \%$.

En los primeros 10 días calendario de enero de cada año, la Administración Aduanera pone a disposición del operador de comercio exterior la categoría obtenida hasta el año calendario anterior.

Al operador de comercio exterior que inicie actividades, la Administración Aduanera le asigna la categoría A y la mantiene hasta finalizar el primer año del plazo de autorización."

"Artículo $21^{\circ}$.-

Al término del plazo del artículo 18, la autorización del operador se renueva conforme a lo siguiente:

a) Las categorías $A$ y $B$, se renuevan automáticamente por el mismo plazo y se computa a partir del primero de febrero del año de la renovación.

b) La categoría C, no se renueva."

28. En la evaluación de la Aduana peruana realizada por el Banco Mundial, se identificó que el sistema sancionatorio vigente era un elemento que atenta contra el buen resultado de la gestión fiscalizadora de la aduana en el Perú. La Aduana descubre incumplimientos que son sancionados con muy bajas sanciones, lo que impide un cambio de comportamiento de los operadores incumplidores - Banco Mundial, "Resultados del Customs Assessment Trade (CAT-R) Preparado Para la Administración Aduanera de Perú", 17 de octubre de 2017, https://www.sunat. gob.pe/orientacion/delnteres/ReporteCATT-Peru2017.pdf-.

29. Conforme señala Rafael Reaño, las infracciones materia de la facultad discrecional, en general, se refieren a la presentación o transmisión de la información del manifiesto de carga y documentos vinculados; incorporación de documentos al manifiesto de carga; actos relacionados con el ingreso o salida de mercancías o medios de transporte; información para la regularización del régimen aduanero; información de la declaración aduanera de mercancías; no proporcionar, exhibir o transmitir la información o documentación en la forma y plazos establecidos; presentar la mercancía fuera del plazo; no destinar la mercancía a la modalidad de despacho anticipado cuando sea obligatorio; no extraer o entregar las muestras de la mercancía; no retirar del país el vehículo para fines turísticos al haber excedido el plazo de permanencia autorizado. 
las medidas de seguridad, a las normas de autorización o no someterse al control. Los supuestos de inaplicación fueron establecidos por la propia SUNAT, teniendo en cuenta no solamente las limitaciones impuestas por el Estado de Emergencia de la COVID-1930, sino también por la implantación de los nuevos procedimientos digitalizados en el marco del FAST. ${ }^{31}$

Además, respecto a las infracciones que se hubieran cometido hasta el 31 de diciembre del 2019 y estuvieran pendientes de pago, se estableció un Régimen de Gradualidad con rebajas de hasta el $90 \% .{ }^{32}$

Finalmente, respecto al récord de cumplimiento de los operadores, que se mide en función de las sanciones cometidas y que puede significar la pérdida de su autorización ${ }^{33}$, la última norma de alivio del año fue precisamente la que modificó la fórmula de medición y excluyó el año 2020 del historial de cumplimiento del OCE. ${ }^{34}$

Estos alivios al usuario aduanero han producido una elevación del nivel de satisfacción frente a la Administración -la encuesta SUNAT otorgó un nivel de 4 sobre 5 , donde el $71 \%$ marcó las opciones satisfecho o muy satisfecho con el accionar de la administración aduanera durante la pandemia-. ${ }^{35}$

\section{A MODO DE CONCLUSIÓN}

A partir del análisis de la normatividad aduanera durante el Estado de Emergencia y la Nueva
Normalidad COVID-19, podemos arribar a las siguientes conclusiones:

a) El Estado de Emergencia encontró a la Administración Aduanera en un proceso de transformación tecnológica —Proyecto FAST - y con un nuevo marco legal - Modificación del Régimen de Operadores y de Infracciones y Sanciones con el Decreto Legislativo 1433 y el Decreto Supremo 4182019-EF- los cuales se encontraban en pleno proceso de implementación al llegar la COVID-19 al Perú.

b) El Estado Peruano, al decretar el Estado de Emergencia, estableció los lineamientos para continuar con su programa de Gobierno Digital teniendo como eje el procedimiento administrativo electrónico en todas las entidades públicas; y para el caso específico del comercio exterior dictó las normas para que el transporte de carga continúe operando y se garantice la cadena logística de comercio internacional, utilizando documentos electrónicos como regla tanto en la administración como en los operadores privados -Decreto Legislativo 1492 - y regulando la exportación de medicamentos y alimentos necesarios para la lucha contra la COVID-19, así como estableciendo arancel cero para su importación -Decretos Supremos N ${ }^{\circ}$ 051-2020EF y 059-2020-EF-.

La Administración Aduanera, para hacer frente a la pandemia en las etapas de ais-

30. Cfr. Resoluciones de Superintendencia N 06-SUNAT-300000, 08-SUNAT-300000, 13-SUNAT-300000, 14-SUNAT$300000,16-S U N A T-300000$ y 19-SUNAT-300000.

31. Cfr. Resoluciones de Superintendencia N $01-S U N A T-300000,12-S U N A T-300000,14-S U N A T-300000$ y 26-SUNAT-300000.

32. Cfr. Resolución de Superintendencia $N^{\circ} 156-2020-S U N A T$.

33. Cfr. Artículo 21 del Reglamento de la LGA.

34. Cfr. Resolución de Superintendencia N²26-2020-SUNAT

35. "Resultado de encuesta de satisfacción a los operadores de comercio exterior", en SUNAT, acceso el 9 de julio de 2021, https://www.sunat.gob.pe/operatividadaduanera/novedades/aduanas/comunicados/2021/enero/ co050121.html. 
lamiento y reactivación, dictó una serie de normas destinadas a digitalizar todos sus procedimientos -Administración Aduanera 2.0 o Aduana paperless - y otras destinadas al alivio de los usuarios aduaneros afectados por la crisis — suspensión de plazos, beneficios tributarios e inaplicación de sanciones-.

c) La sinergia entre los nuevos procesos digitales, nuevas normas y alivios a los usuarios, no sólo significó un paso adelante en la implementación de la Administración Aduanera 2.0 - con 12 de los 13 regímenes aduaneros digitalizados y la implementación de una MPV - y logró revertir la tendencia a la baja de la recaudación aduanera, sino también significó el reforzamiento del pilar Aduana-empresa con niveles de satisfacción de los usuarios aduaneros de 4.03 en una escala de 1 a 5 , el cual representa el $80.6 \%$ del nivel de satisfacción. Considerando las categorías "satisfecho" y "muy satisfecho", el resultado alcanzado fue de $71 \%$ de aceptación.

d) Finalmente, el nuevo Régimen de Infracciones y Sanciones, más razonable que el anterior, logró mantener su vigencia gracias a la postergación de sanciones con Resoluciones discrecionales durante el Estado de emergencia y con la exclusión de las infracciones cometidas el año 2020 del record de cumplimiento de los OCE.

Con estas medidas la legislación aduanera trató de contribuir a que la contracción económica del país no resulte más grave - $-12 \%$ del PBI en el 2020-y, en todo caso, colocar las bases para hacer viable la reactivación económica del país, al menos los cuadros macroeconómicos proyectados dan una esperanza de crecimiento del PBI en el $2021-9 \%$ - los efectos de la nueva cepa, la segunda ola y la vacuna, además de las elecciones presidenciales confirmarán si estos buenos presagios son ciertos - ver figura 4-. 
Figura 4

LA ECONOMÍA LATINOAMERICANA POST-COVID-19

\section{La economía latinoamericana poscoronavirus}

Variación real del PIB en países latinoamericanos

seleccionados en 2020 y 2021 (\%)

\section{口 $2020 \quad 2021$}

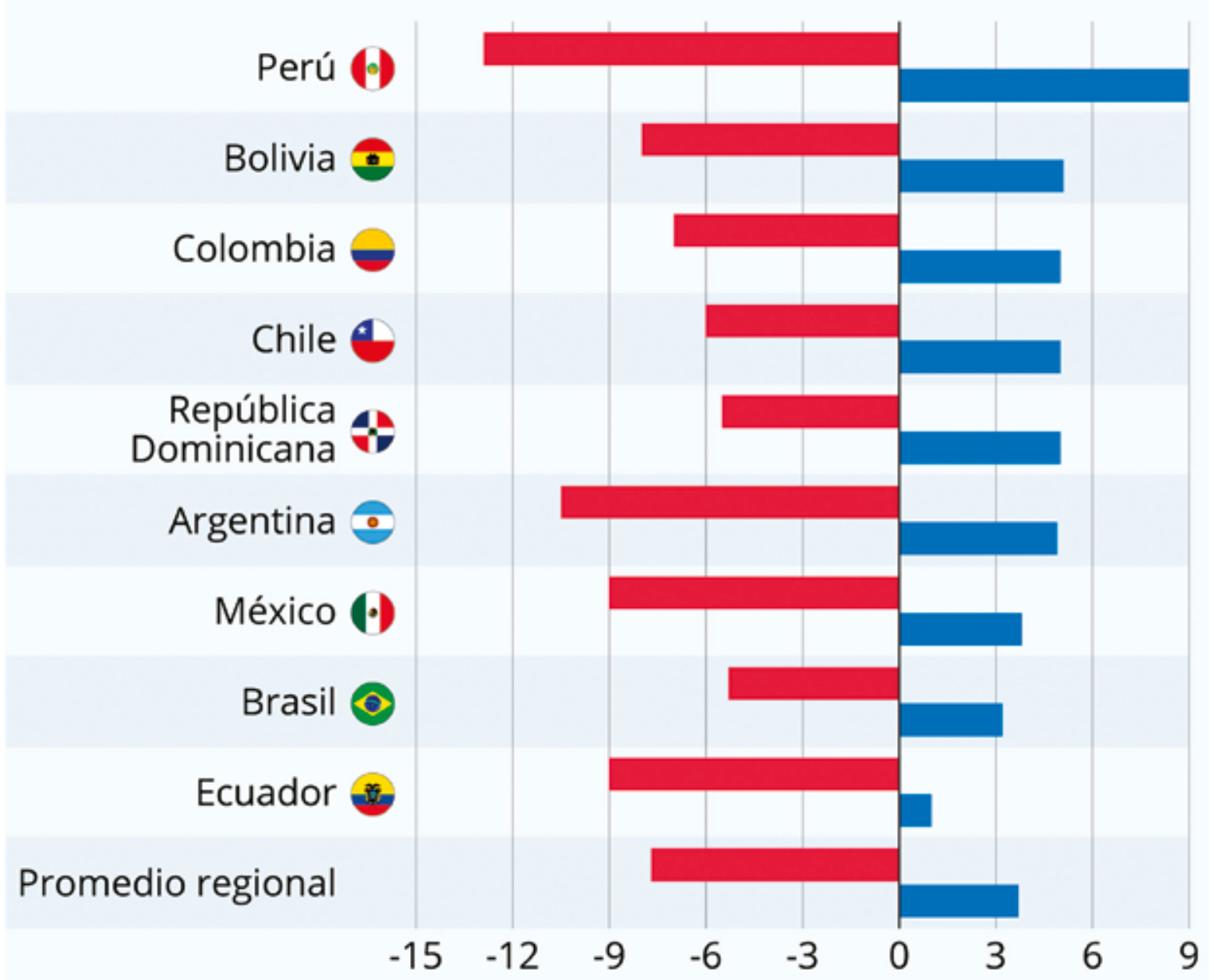

Previsiones de diciembre de 2020 basadas en precios constantes en dólares de 2010. Fuente: CEPAL 